\title{
Hemodynamic effects of dexmedetomidine during intra-operative electrocorticography for epilepsy surgery
}

The dominant challenge in epilepsy surgery is precise delineation of the epileptogenic zone in the brain. Noninvasive techniques such as video electroencephalography (EEG), single photon emission computerized tomography (SPECT), positron emission tomography (PET), magnetoencephalography (MEG), and high-resolution MRI all lack sufficient spatial resolution and sensitivity in many patients. Extraoperative seizure mapping with subdural and/or depth electrodes can be appropriate in many cases, but is not without significant drawbacks. Disadvantages include the requirement for more than one major intracranial operation, need for the patient to be reasonably compliant, insufficient seizure capture, and potential surgical complications including hemorrhage and infection. In addition, electrode coverage may not be adequate, and areas such as insular and frontobasal cortex can be technically challenging to access. Intraoperative electrocorticography (ECoG) avoids many of these disadvantages (notably aside from inadequate coverage), but at the expense of capturing only interictal EEG data. The quality of intraoperative EEG data, therefore, is of paramount importance during one-stage epilepsy surgeries in which ECoG is employed.

Dexmedetomidine is an intravenous alpha 2-adrenergic receptor agonist whose use in neurological surgery has blossomed over the past several years due to its sedation properties and desirable neurophysiological profile. ${ }^{[1]}$ This medication has been extensively studied in the context of various neurosurgical pathologies and treatment modalities including awake brain tumor surgery, functional MRI scanning, and endovascular aneurysm treatment. ${ }^{[2-4]}$ Its use has also been studied with electroconvulsive therapy, where postprocedural

\begin{tabular}{|l|l|}
\hline \multicolumn{2}{|c|}{ Access this article online } \\
\hline Quick Response Code: & Website: \\
\hline & www.ruralneuropractice.com \\
\cline { 2 - 2 } & \\
\hline
\end{tabular}

agitation was found to be improved but induced seizure duration not apparently altered. ${ }^{[5,6]}$

The primary concerns regarding dexmedetomidine use in epilepsy surgery revolve around two issues, alteration of the EEG profile and hemodynamic effects, particularly bradycardia and hypotension. Dexmedetomidine does not seem to be a significant EEG confounder. ${ }^{[7]}$ Its intraoperative hemodynamic profile also seems to be safe, although this particular aspect has not previously been specifically addressed within the context of epilepsy surgery. ${ }^{[8]}$ The present study addresses this concern directly with a series of patients undergoing ECoG-guided anterior temporal lobectomy and amygdalohippocampectomy, the most common resective surgery for epilepsy in the adult population..$^{[9]}$ The findings are that dexmedetomidine anesthesia does generate a measurable but clinically insignificant hemodynamic effect when used in this context, and that it does not otherwise adversely impact surgery. This study is a useful contribution to the body of data on which the practice of epilepsy surgery is based. Further studies such as this will allow epilepsy surgery to continue to become more safe and more efficacious.

William C. Gump

Division of Pediatric Neurosurgery, Norton Neuroscience Institute, Louisville, Kentucky, USA

Address for correspondence: Dr. William C. Gump, Norton Neuroscience Institute, 210 East Gray Street, Suite 1102 Louisville, Kentucky - 40202, USA. E-mail: william.gump@nortonhealthcare.org

\section{References}

1. Bekker A, Sturaitis MK. Dexmedetomidine for neurological surgery. Neurosurgery 2005;57(Suppl 1):1-10.

2. Shen SL, Zheng JY, Zhang J, Wang WY, Jin T, Zhu J, et al. Comparison of dexmedetomidine and propofol for conscious sedation in awake craniotomy: A prospective, double-blind, randomized, and controlled clinical trial. Ann Pharmacother 2013;47:1391-9.

3. Bernal B, Grossman S, Gonzalez R, Altman N. FMRI under sedation: What is the best choice in children? J Clin Med Res 2012;4:363-70.

4. Lee HH, Jung YJ, Choi BY, Chang CH. Usefulness of dexmedetomidine 
during intracerebral aneurysm coiling. J Korean Neurosurg Soc 2014;55:185-9.

5. Mizrak A, Koruk S, Ganidagli S, Bulut M, Oner U. Premedication with dexmedetomidine and midazolam attenuates agitation after electroconvulsive therapy. J Anesth 2009;23:6-10.

6. Begec Z, Toprak HI, Demirbilek S, Erdil F, Onal D, Ersoy MO. Dexmedetomidine blunts acute hyperdynamic responses to electroconvulsive therapy without altering seizure duration. Acta Anaesthesiol Scand 2008;52:302-6.

7. Mason KP, O’Mahony E, Zurakowski D, Libenson MH. Effects of dexmedetomidine sedation on the EEG in children. Paediatr Anaesth 2009;19:1175-83.
8. Bekker A, Sturaitis M, Bloom M, Moric M, Golfinos J, Parker E, et al. The effect of dexmedetomidine on perioperative hemodynamics in patients undergoing craniotomy. Anesth Analg 2008;107:1340-7.

9. Chaitanya G, Arivazhagan A, Sinha S, Madhusudan Reddy KR, Thennarasu K, Bharath RD, et al. Hemodynamic effects of Dexmedetomidine during intra-operative electrocorticography for epilepsy surgery. J Neurosci Rural Pract 2014;5:S17-21.

How to cite this article: Gump WC. Hemodynamic effects of dexmedetomidine during intra-operative electrocorticography for epilepsy surgery. J Neurosci Rural Pract 2014;5:1-2.

Source of Support: Nil. Conflict of Interest: None declared.

\section{"Ouick Response Code" link for full text articles}

The journal issue has a unique new feature for reaching to the journal's website without typing a single letter. Each article on its first page has a "Quick Response Code". Using any mobile or other hand-held device with camera and GPRS/other internet source, one can reach to the full text of that particular article on the journal's website. Start a QR-code reading software (see list of free applications from http://tinyurl.com/ yzlh2tc) and point the camera to the QR-code printed in the journal. It will automatically take you to the HTML full text of that article. One can also use a desktop or laptop with web camera for similar functionality. See http://tinyurl.com/2bw7fn3 or http://tinyurl.com/3ysr3me for the free applications. 